\title{
Enzymes from cold-adapted microorganisms The class C $\beta$-lactamase from the antarctic psychrophile Psychrobacter immobilis A5
}

\author{
Georges FELLER ${ }^{1}$, Zoubir ZEKHNINI ${ }^{1}$, Josette LAMOTTE-BRASSEUR ${ }^{2}$ and Charles GERDAY ${ }^{\prime}$ \\ ' Laboratoire de Biochimie, Institut de Chimie B6, Université de Liège, Belgium \\ 2 Centre d'Ingénierie des Proteines, Institut de Chimie B6, Université de Liège, Belgium
}

(Received 21 August/6 December 1996) - EJB 96 1249/3

\begin{abstract}
A heat-labile $\beta$-lactamase has been purified from culture supernatants of Psychrobacter immobilis A5 grown at $4{ }^{\circ} \mathrm{C}$ and the corresponding chromosomal ampC gene has been cloned and sequenced. All structural and kinetic properties clearly relate this enzyme to class $C \beta$-lactamases. The kinetic parameters of $P$. immobilis $\beta$-lactamase for the hydrolysis of some $\beta$-lactam antibiotics are in the same range as the values recorded for the highly specialized cephalosporinases from pathogenic mesophilic bacteria. By contrast, the enzyme displays a low apparent optimum temperature of activity and a reduced thermal stability. Structural factors responsible for the latter property were analysed from the three-dimensional structure built by homology modelling. The deletion of proline residues in loops, the low number of arginine-mediated $\mathrm{H}$-bonds and aromatic-aromatic interactions, the lower global hydrophobicity and the improved solvent interactions through additional surface acidic residues appear to be the main determinants of the enzyme flexibility.
\end{abstract}

Keywords: psychrophile; extremophile; Antarctic; $\beta$-lactamase; cephalosporinase.

Psychrophilic microorganisms represent a major class of the microbial world if one considers the vast extent of permanently cold environments on Earth (deep-sea waters, polar and alpine regions). In spite of the diversity and abundance of these extremophiles, the numerous physiological and biochemical adaptations to the life at temperatures close to $0^{\circ} \mathrm{C}$ remain poorly documented $[1,2]$. The dominating character of cold-adapted enzymes is probably their enhanced turnover number $\left(k_{\text {cat }}\right)$ and catalytic efficiency $\left(k_{\mathrm{ca}} / K_{\mathrm{m}}\right)$ : improving these kinetic parameters compensates for the reduction of reaction rates at low temperatures and adequate metabolic fluxes are therefore maintained [3]. According to the current hypothesis [4], optimization of the catalytic parameters can originate from the highly flexible structure of these proteins which provides enhanced abilities to undergo conformational changes during catalysis at low temperatures. The usually observed thermal lability is therefore regarded as a consequence of the folded structure flexibility. The molecular origin of this flexibility has been analysed from the primary structure of some psychrophilic bacterial enzymes. All studies suggest a potentially low number of weak interactions stabilizing the folded conformation $[5,6]$. We report here the kinetic characterization, the nucleotide sequence and a structural analysis of the $\beta$-lactamase secreted by the antarctic psychrophile Psychrobacter immobilis A5, a gram-negative bacterial strain collected in an environment ranging in temperature from -20 to $+2{ }^{\circ} \mathrm{C}$. A brief account of some properties of another $\beta$-lactamase from a closely related strain has been given recently [7].

Correspondence to $\mathrm{G}$. Feller, Laboratoire de Biochimie, Institut de Chimie B6, Université de Liège, B-4000 Liège-Sart Tilman, Belgium

Fax: +3243663364 .

Enzyme. $\beta$-lactamase (EC 3.5.2.6).

Note. The novel nucleotide sequence data reported here have been submitted to the GenBank/EMBL sequence data banks and are available under the accession number X83586.
Bacterial $\beta$-lactamases hydrolyse the amide bond of the $\beta$ lactam ring of penicillin-derived antibiotics yielding biologically inactive compounds. Due to their critical role in bacterial antibiotic resistance, the substrate specificities and the action mechanisms of mesophilic $\beta$-lactamases have been widely studied. Several primary structures are known and the three-dimensional structures of some $\beta$-lactamases have been solved at high resolution [8-10]. $\beta$-lactamases are, therefore, appropriate candidates for a detailed comparison of the functional and structural properties of a psychrophilic enzyme with its mesophilic counterparts. $\beta$-lactamases are commonly classified into four groups. Class A (penicillinases), class C (cephalosporinases) and class D enzymes belong to the active-serine enzyme superfamily and differ at the level of their primary structure, whereas class B $\beta$-lactamases rely on the presence of a $\mathrm{Zn}^{2+}$ in their active site.

\section{MATERIALS AND METHODS}

Sources. P. immobilis A5 was isolated from frozen organic debris in Terre Adelie near the antarctic station Dumont d'Urville $\left(66^{\circ} 40^{\prime} \mathrm{S}, 140^{\circ} 01^{\prime} \mathrm{E}\right)$. The class $\mathrm{C} \beta$-lactamase from the mesophile Enterobacter cloacae Q908R was a gift from Prof. J. M. Frère (University of Liège). Manufacturers of the $\beta$-lactam compounds are those previously cited $[11,12]$.

$\beta$-lactamase purification. The strain was cultivated at $4{ }^{\circ} \mathrm{C}$ for 4 days in 31 of TYK medium containing $16 \mathrm{~g} / 1$ bactotryptone, $5 \mathrm{~g} / \mathrm{l}$ yeast extract, $2.5 \mathrm{~g} / \mathrm{K}_{2} \mathrm{HPO}_{4}$, $\mathrm{pH}$ 7.6. After centrifugation at $23000 \mathrm{~g}$, the culture supernatant was concentrated to $300 \mathrm{ml}$ and diafiltered against $25 \mathrm{mM}$ Tris/ $\mathrm{HCl}, \mathrm{pH} 8.0$, by using a Minitan tangential flow ultrafiltration unit (Millipore) fitted with PTGC membranes (10-kDa retention limit). The sample was loaded on a DEAE-cellulose column $(3.0 \mathrm{~cm} \times 25 \mathrm{~cm})$ equilibrated in the above mentioned buffer and eluted with a $\mathrm{NaCl}$ linear gradient ( $220 \mathrm{ml}$ to $220 \mathrm{ml}, 0$ to $0.2 \mathrm{M} \mathrm{NaCl}$ ) applied after 
Table 1. Purification of the extracellular $\beta$-lactamase from $P$. immobilis A5.

\begin{tabular}{lcccrr}
\hline Purification step & Volume & Protein & Specific activity & Yield & Purification \\
\hline & $\mathrm{ml}$ & $\mathrm{mg}$ & $\mu \mathrm{mol} \cdot \mathrm{min}^{-1} \cdot \mathrm{mg}^{-1}$ & $\%$ & - fold \\
Culture supernatant & 2800 & 538 & 0.9 & 100 & 1.0 \\
Diafiltration & 290 & 239 & 1.0 & 85 & 65 \\
DEAE-cellulose & 34 & 21.2 & 31.1 & 51 & 3.5 \\
Sephacryl S-200 & 56 & 5.3 & 2094 & 24 & 2327 \\
Phenylboronic-acid-agarose & 20 & 0.06 & & 24 \\
\hline
\end{tabular}

$100 \mathrm{ml}$ buffer elution. Fractions containing the $\beta$-lactamase activity were concentrated to $10 \mathrm{ml}$ and applied onto a Sephacryl S-200 column $(2.5 \mathrm{~cm} \times 100 \mathrm{~cm})$ eluted with $25 \mathrm{mM}$ Tris $/ \mathrm{HCl}$, $\mathrm{pH}$ 8.0. The active fractions were adjusted to $0.5 \mathrm{M} \mathrm{NaCl}$ and concentrated to $5 \mathrm{ml}$. The sample was then loaded on a phenylboronic-acid-agarose column $(1.5 \mathrm{~cm} \times 20 \mathrm{~cm})$ prepared according to [13] and eluted with $25 \mathrm{mM}$ Tris/ $\mathrm{HCl}, 0.5 \mathrm{M} \mathrm{NaCl}$, $\mathrm{pH}$ 8.0. To elute the enzyme in a sharp peak, $125 \mathrm{mM} \mathrm{K}_{2} \mathrm{~B}_{4} \mathrm{O}_{7}$. $4 \mathrm{H}_{2} \mathrm{O}$ was added to the irrigating buffer after $24 \mathrm{ml}$ elution.

Enzyme assay and kinetic parameters. Standard assay of $\beta$-lactamase activity was carried out at $25^{\circ} \mathrm{C}$ using $300 \mu \mathrm{M}$ nitrocefin as substrate in $50 \mathrm{mM}$ sodium phosphate, $\mathrm{pH} 7.5$, containing $100 \mu \mathrm{g} / \mathrm{ml}$ BSA. Activities towards the chromogenic substrate were recorded in a temperature-regulated Uvikon 860 spectrophotometer (Kontron) and were calculated using an absorption coefficient of $15000 \mathrm{M}^{-1} \mathrm{~cm}^{-1}$ at $482 \mathrm{~nm} \mathrm{[14].} \mathrm{The}$ values of $k_{\text {cat }}$ and $K_{\mathrm{m}}$ for nitrocefin and for cefazolin were measured by analysing the complete progress curves of the reaction [11]. For cephalexin, benzylpenicillin and ampicillin, $K_{\mathrm{m}}$ values were measured as $K_{\mathrm{j}}$ by using $100 \mu \mathrm{M}$ nitrocefin as the reporter substrate [12], and $k_{\text {cat }}$ values were obtained with saturating concentrations of substrate.

Analytical procedures. Protein concentrations were determined using the Coomassie protein reagent (Pierce). SDS/PAGE and isoelectric focusing were run essentially as described by the supplier of the electrophoretic equipment (Hoeffer Scientific Instruments). The $\mathrm{N}$-terminal amino acid sequence of the native enzyme was determined using a pulsed-liquid-phase protein sequenator (Applied Biosystem 477A) equipped with an on-line $120 \mathrm{~A}$ phenylthiohydantoin analyzer.

Cloning and sequencing the ampC gene. Genomic DNA of $P$. immobilis A5 was partially digested with Sau3AI and the resulting fragments were inserted into the single $B a m H I$ site of pBGS18 $8^{+}$[15]. The ligated DNA fragments were electroporated in Escherichia coli RR1 cells and the transformants" were selected on Luria-Bertani agar plates containing $50 \mu \mathrm{g}$ kanamycin/ $\mathrm{ml}$. The temperature of growth and incubation was controlled as previously described [16]. Plates were sprayed with a sterile solution of nitrocefin. Among 3000 transformants screened, one clone developed a red halo corresponding to the hydrolysis of nitrocefin. The ampC-gene-containing DNA fragment was subcloned into the polylinker of the phagemids pGEM3Zf $\mathrm{f}^{+}$and $\mathrm{f}^{-}$. Single-stranded DNA was obtained by infecting pGEM3Zftransformed $E$. coll JM109 cells with the helper phage M13K07, inducing the bacteriophage f1 replication (pGEM Single Strand System, Promega). The nucleotide sequence of both strands was determined using Sequenase (US Biochemical Corp.).

Molecular modelling. The model for the structure of $P . \mathrm{im}$ mobilis $\beta$-lactamase was built using the homology modelling program COMPOSER [17, 18], starting from the atomic coordinates of E. cloacae cephalosporinase (Brookhaven Protein Data Bank, filename 1BLT). The structure was minimized within the AMBER molecular mechanics V4.1 framework [19] in order to release some short contacts. Both programs were run on a Silicon Graphics Indy workstation.

\section{RESULTS}

$\boldsymbol{\beta}$-lactamase production and purification. The antarctic bacterial strain $P$. immobilis A5 is able to grow between $0^{\circ} \mathrm{C}$ and $25^{\circ} \mathrm{C}$. However, optimal growth yield and $\beta$-lactamase secretion were found below $5^{\circ} \mathrm{C}$. The effects of temperature on growth and on enzyme secretion of $P$, immobilis and of some other antarctic bacteria have been described elsewhere [20]. $\beta$-lactamase secretion into the culture supernatant followed bacterial growth and about $15 \%$ of the total activity remained cell associated at the early stationary phase. No induction of $\beta$-lactamase production was recorded following addition of $10 \mu \mathrm{g} / \mathrm{ml}$ benzylpenicillin, $\Delta^{3}$-desacetoxy-7-aminocephalosporonate or 6-aminopenicillinic acid whereas $5 \mathrm{~g} / \mathrm{l} \mathrm{NaCl}$ inhibited $50 \%$ of the enzyme production.

The $\beta$-lactamase was purified from culture supernatant of $P$. immobilis grown at $4^{\circ} \mathrm{C}$, using a phenylboronic-acid-agarose column at the final step (Table 1). Because the enzyme is not bound to this affinity medium (but is only retarded), two other chromatographic steps were required in order to remove contaminating peptides and pigments. About $20 \mu \mathrm{g} \beta$-lactamase were purified from 11 culture; SDS/PAGE revealed a single band and no significant contamination was detected by N-terminal amino acid sequencing. According to the purification yield $(24 \%), \beta-$ lactamase secretion in the supernatant was estimated to $85 \mu \mathrm{g} / \mathrm{l}$.

Characterization of $\boldsymbol{P}$. immobilis $\boldsymbol{\beta}$-lactamase. The molecular mass of the native $\beta$-lactamase was found to be $41 \mathrm{kDa}$ by SDS/ PAGE and its pI to be 5.4 as indicated by isoelectric focusing under non-denaturing conditions. The activity of $P$. immobilis $\beta$ lactamase is unaffected by $5 \mathrm{mM}$ EDTA indicating that it does not belong to the class $B$ metalloenzymes. By contrast, incubation at $4{ }^{\circ} \mathrm{C}$ in the presence of $10 \mu \mathrm{M}$ oxacilline results in a complete inhibition of the activity towards nitrocefine. Kinetic parameters for the hydrolysis of three cephalosporins (nitrocefin, cephalexin and cefazolin) and two penicillins (benzylpenicillin and ampicillin) have been determined. As shown in Table 2, cephalosporins are good substrates for $P$. immobilis $\beta$-lactamase. This catalytic profile is similar to that determined for other class C $\beta$-lactamases from mesophilic bacteria $[11,12]$.

Stability and thermodependence of activity. The enzyme is stable in the high $\mathrm{pH}$ range with an optimum value near $\mathrm{pH} 8.5$ (Fig. 1A). Inactivation at neutral and low $\mathrm{pH}$ suggests that protonation of histidyl residues destabilizes the psychrophilic enzyme. The denaturation curves of $\beta$-lactamases from $P$. immobilis and from the mesophilic $E$. cloacae clearly illustrate the low thermal stability of the psychrophilic enzyme (Fig. 1B). The half-time for inactivation of the psychrophilic $\beta$-lactamase at 
Table 2. Kinetic parameters for the hydrolysis of some $\beta$-lactam antibiotics by the psychrophilic and mesophilic class $\mathrm{C} \beta$-lactamases. All data have been recorded at $30^{\circ} \mathrm{C}$. SD $\leqslant 10 \%$ of the values reported for the psychrophilic enzyme. Data for the mesophilic enzymes are from [11, 12].

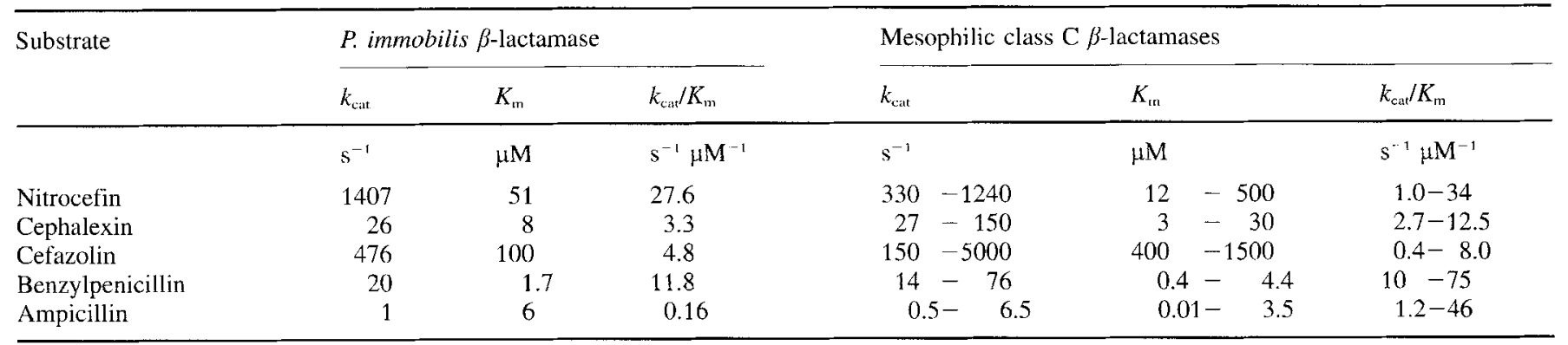

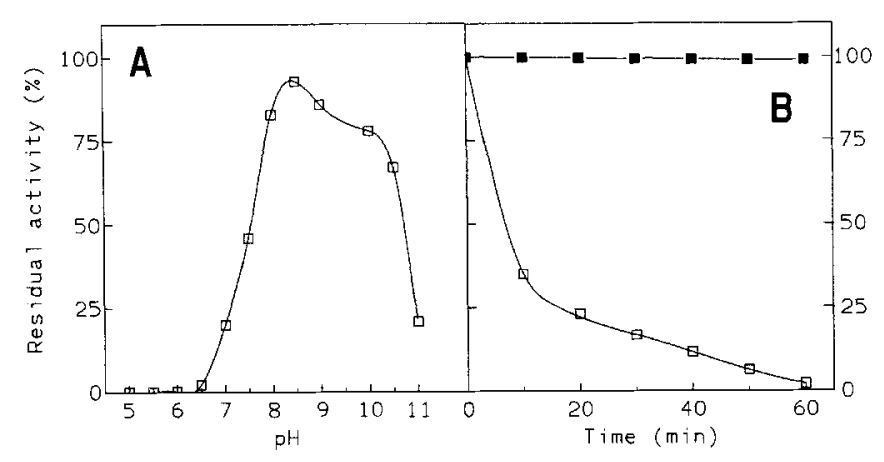

Fig. 1. Stability of $P$. immobilis $\beta$-lactamase. (A) $\mathrm{pH}$ stability recorded after $24 \mathrm{~h}$ incubation at $4^{\circ} \mathrm{C}$ in $25 \mathrm{mM}$ each acetate, Pipes, Tris and Caps at the indicated $\mathrm{pH}$ values. Residual activities were recorded using nitrocefin as substrate. (B) Thermal stability of $\beta$-lactamase from $P$. immobilis ( $\square$ ) and E. cloacae Q908R ( $)$ at $50^{\circ} \mathrm{C}$ in $25 \mathrm{mM}$ Tris/ $\mathrm{HCl}$, $\mathrm{pH} 8.5$, containing $100 \mu \mathrm{g} / \mathrm{ml}$ BSA.

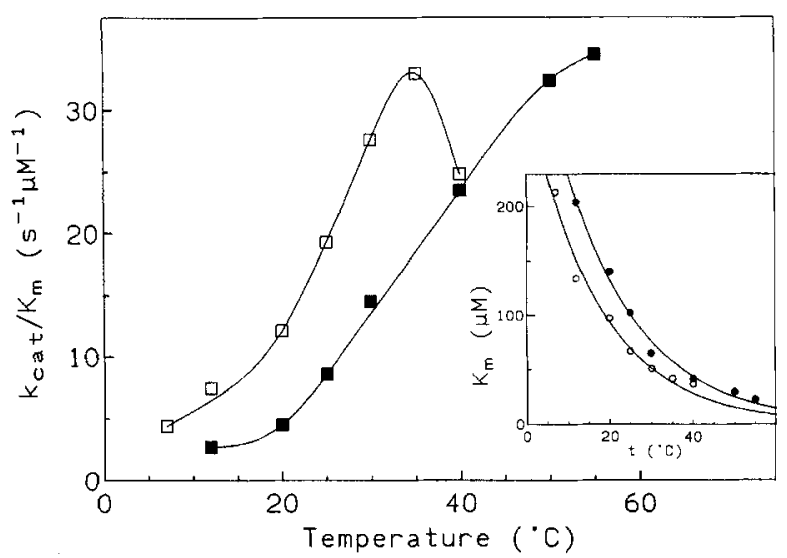

Fig. 2. Temperature dependence of the nitrocefin hydrolysis. Kinetic parameters of $\beta$-lactamase from P. immobilis $(\square)$ and E. cloacae Q908R (E) for the hydrolysis of nitrocefin were recorded at increasing temperatures as described in the Materials and Methods section.

$50^{\circ} \mathrm{C}$ is about $7 \mathrm{~min}$ whereas the activity of the mesophilic enzyme remains unaltered for more than $1 \mathrm{~h}$ in these conditions. Fig. 2 illustrates the effect of temperature on the kinetic parameters of $\beta$-lactamases from the psychrophilic and mesophilic strains. The thermodependence curves of the $k_{\text {cat }} / K_{\mathrm{m}}$ values display a shift of the apparent optimal temperature of activity of about $20^{\circ} \mathrm{C}$ towards lower temperatures in the case of the psychrophilic enzyme. As the decrease in $K_{\mathrm{m}}$ values with temper- ature is similar for both enzymes (Fig. 2), this difference mainly arises from the thermodependence of $k_{\text {cat }}$.

Sequence of the chromosomal ampC gene. The structural gene of the $\beta$-lactamase was cloned from a genomic library of $P$. immobilis in E. coli. To circumvent thermal denaturation of the cloned gene products, $E$. coli transformants were allowed to grow overnight at $25^{\circ} \mathrm{C}$. When sprayed with nitrocefin, one clone produced a red halo of substrate hydrolysis, demonstrating the expression of an active recombinant $\beta$-lactamase. The 14$\mathrm{kb}$ cloned DNA fragment was also found to confer ampicillin resistance $(50 \mu \mathrm{g} / \mathrm{ml})$ to the host strain in addition to the plasmid-encoded kanamycin resistance. Taking advantage of the latter property, the structural $a m p C$ gene was located on a $2.4-\mathrm{kb}$ SphI-Sau3AI restriction fragment which was sequenced on both strands. The primary structure of the $\beta$-lactamase presursor from $P$. immobilis was deduced from the nucleotide sequence and is shown in Fig. 3. Determination of the N-terminal amino acid sequence of the purified native enzyme indicates that a peptide made of 39 amino acid residues is cleaved from the $\beta$-lactamase precursor. However, a potential signal-peptidase-cleavage site which fulfils the $-3,-1$ rule [21] is also found 23 residues downstream from the $\mathrm{N}$-terminal formylmethionine (Fig. 3), suggesting that the $\beta$-lactamase precursor has the structure of a preproenzyme. The mature $P$. immobilis $\beta$-lactamase is composed of 362 amino acid residues with a predicted molecular mass of $40321 \mathrm{Da}$, in good agreement with the electrophoretic estimation. Boxed in Fig. 3 are the four structural and functional elements conserved in $\beta$-lactamases [22], supplying most of the groups involved in the catalysis and in the active-site architecture $[9,10,23,24]$. The active-site serine is found at position 63 in the first conserved element. Sequence alignment with six other class $\mathrm{C} \beta$-lactamases (Fig. 4) indicates that the $P$. immobilis enzyme possesses between $38 \%$ (E. coli) and $43 \%$ (Pseudomonas aeruginosa) amino acid sequence identity when compared with $\beta$-lactamases from mesophilic bacteria.

Structural analysis of $\boldsymbol{P}$. immobilis $\beta$-lactamase. Striking similarities in the general folding have been noted in the crystal structures of two solved class $\mathrm{C} \beta$-lactamases $[23,24]$. This allowed the building of a three-dimensional model of the psychrophilic enzyme based on $E$. cloacae $\beta$-lactamase atomic coordinates at $0.2-\mathrm{nm}$ resolution (coordinates of the Citrobacter freudii enzyme are not available). The rmsd for the $\mathrm{C} \alpha$ atoms from both structures was $0.127 \mathrm{~nm}$, with the largest differences observed in the loop between helices $\alpha 5$ and $\alpha 6$ where two proline residues are lacking in $P$. immobilis $\beta$-lactamase. The molecular architecture follows the pattern of the known $\beta$-lactamases structures with an all-helical domain and a mixed $\alpha / \beta$ domain; the 
GATCGTATGCCAATCGCTTGATCCGACGCCATCATTT GCAGAGTACTGGCACATGGGTCCGATGATAATACGGTTGGCTAGTGTTATTTGCCCAAGTTTC AAACGCGAAAAAAGITGGCTCATCATTATCCTTAMAAAACGCGCCTAAAGGGACCG,GAAATAA AATGCAAAAGCGATATAATGATTTGTATGGCTTATATGACTTAACTTATATACTTAACTTATA TGATTATCGCTTCAMTAGTTGATGGGGATGAATCGTTATTTTTATACTCCACATTGCATTTTA TGTCGTTCACTTTCGAGAGTCATTACTCTATATCTACTAATGCACGTCATTATATAACCCCCA CTGCCAAATTAATCCAATCAGTATACACAAAAAAACAGGTAATTGCAAAAAATGGGGTGATAA ATAGTGGTTAAAACTCCTACATTTAGCAATCATTTTTTCAATCAAMTAGACCGCATCAATAA

Met Lys l.eu Phe Thr Ser Thr l.eu Thr Ala l.ys lys Ser Ser -10 RBS ATAACTT ATG AMA CTA TTT ACA TCA ACA CTG ACT GCT AAA AAA TCA TCT Thr His lys Pro Leu lle Ser leu Ala! Leu Ser Val Leu fle Ser Thr
ACT CAC AAA CCC CTC ATC ACC CTA GOOG CrT ACC GTA CTC ATT TCG ACC Leu leu Ite Ser Gilu Thr Ala GIn Ala ${ }^{-1}$ Ala Asp AIe Aso Asp Arg Leu Glu Gln Glu Val Asp Lys Gln Ala Lys Gln Leu Met Ala Gln Tyr Gln Ile Pro Gly Met Ala Phe Gly Ile Ile Val Asp Gly Lys Ser His Phe Tyr Asn Tyr Gly Leu Ala Asp Lys Gln Arg Asn Gln Pro Val Ser Gln TAT AAT TAT GGT TTG GCT GAT AAG CAA CGC AAT CAG CCA GTA TCA GAG Asp Thr Ile Phe Glu Leu Gly Ser Val Ser Lys Thr Phe Ala Ala Thr GAC ACG ATA TTT GAG CTG GGT |TCT GTG AGC AAA ACC TTT GCT GCC ACG Leu Ala Ser Tyr Ser Glu Leu Asn Gly Thr Leu Ser Leu Asp Asp Thr TTG GCC AGT TAT TCT GAG TTA AAT GGT ACC TTA TCA CTC GAT GAT ACG Ala Asp Lys Tyr Ile Pro Tyr Leu Lys Asn Ser Ala Ile Gly Asn Thr Lys Leu Ile Ser Leu Val Thr Tyr Ser Ala Gly Gly Tyr His Tyr Ar Cys Leu Lys Thr Leu Glu Asn Asn Lys Glu Leu Leu Gln Tyr Tyr Lys
TGC CTG AAG ACA TTG GAG AAT AAT AAA GAG CTG CTG CAA TAT TAT AAA Ser Trp His Pro Asp Phe Pro val Asn Ser Lys arg Leu Tyr Ser Asm TCT TGG CAT CCT GAC TTT CCT GTC AAT TCA AAA CGC TTA|TAT TCC AAC

Ala Ser Ile Gly Leu Phe Gly Tyr Ile Ser Ala Leu Ser Met His Ser GCC ACC ATC CGA CTG TTT GCC TAT ATC TCT GCC CTG AGT ATG CAC ACT

Asp Tyr Thr Lys Leu Ile Glu Asn Thr Val Leu Pro Ser Leu lys Met 183 GAC TAC ACC AAG CTC ATA GAA AAC ACC GTG TTG CCA TCG CTC AAG ATG 1151

Thr Asn Thr Phe Val Asp Val Pro Ala Asn Lys Met Glu Asp Tyr Ala 199 COCT COC AAT AAA ATG GAA GAT TAT GCC 1199

Phe Gly Tyr Asn Ala Ala Gly Glu Pro Ile Arg Val Asn Pro Gly Met 215 Leu Asp Ala Glu Ala Tyr Gly I le Lys Ser Thr Ser Ala Asp Met Thr 231 \begin{tabular}{ll|l} 
Leu Asp Ala Glu Ala Tyr & Gly Ile lys Ser Thr Ser Ala Asp Met Thr & 231 \\
CTI GAT GCA GAA GCA TAC & GGC ATC AAA TCA ACT AGT GCC GAT ATG ACG 1295
\end{tabular} Arg Phe Met Ala Ala Asn Met Gly Leu Val Thr Val Asp Ser Gln Met 247 Cln Gln Ala leu Asp Asm Asm ArE Lys Cly Tyr Tyr Arr Thr Lys Ser

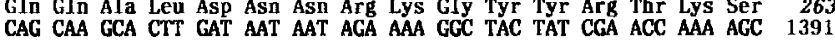
Phe Thr Gln Gly Leu Ala Tro Glu Met Tyr Pro Leu Pro Thr Thr Leu 279 TTT ACG CAA GGG CTG GCT TGG GAG ATG TAT CCA TTA CCG ACG ACC CTA 1439 Gln Gln Leu Val Glu Gly Asn Ser Thr Glu Thr Ile Leu Gln Pro Gln 295 CAG CAG CTT GTA GAA GGC AAT TCA ACA GAA ACC ATA TTA CAA CCT CAG 14B? Pro Ile Gln Leu Asn Glu Pro Pro Thr Pro Val Leu Asn Asp Val Trp 311 $\begin{array}{llll}\text { Val Asn } & \text { Lys Thr Gly Ala Thr Asn Gly Phe Gly Ala Tyr Ile Ala Tyr } & 327 \\ \text { GTT AAC AAA ACA GGC GCC ACC AAT GGT TTT GGC GCT TAC ATC GCT TAT } & 1583\end{array}$ Met Pro Ala Lys Lys Thr Gly Met Phe Ile Leu Ala Asn Lys Asn Tyr 343 ATG CCT GCC AAA AAA ACA GGT ATG TTC ATT TTA GCC AAT AAA AAC TAT 1631 Pro Asn Thr Glu Arg Val Lys Ala Ala Tyr Thr Ile Leu Asp Ser Val 359 CCC AAT ACA GAA CGG GTT AAC GCT GCG TAT ACA ATT TTA GAC AGT GTG 1679

Met Asn Asn ***

ATG AAT AAC TAATGCTCAAAGGAGGGGGATTGCCAAAGAGGTCATTTAGCCCAAAAAATT 136 TCGAGTTTGGGTTTAATAAGTAATGACAGAATAATTGAAAACATAATTCCAATAGGAAGAGCG 1802 GTTAGTAAACTGGCAATCCATACATATATAAAAGTGTTCCAATCAGAAAAACCATTGACATTG 1865 GCGTCTGTAATACCCCCCATGATGTATTCCATTACGACCGCCATACATAAGCCAAAAAGTATA 1928 TTCATTTTCACGGTAGATATATTTGGTAATATTACAGTCAAAAATTTGTTGATAAGCATGGCG 1991 ATCACACCGCCAATAGGGCCAATGCAGACTACCCAAAGTGCAAAAACTTCATCCAATAAGTTA 2054 AAAAGTCAGGGCTGAACCTATGCTTTCCATGTCATTACGAAGTGAGCGTACCACCAATAACGG 2117 AAAAGTAGT CAACTATACTAAATGATCAATATTTTTTAAGATTCGCCATCTAATTATCCACATAATATTCAG 2180 CCTAGTATAACGATATATTTGAAAAAGCAGTCTTGTTCTTTCTGCTTTCTCTACAAACTTA 2243 TGAGTTCGCTAATGATACGGGTAAATATTTTGATAATGACATCAAAGATGGGGCACATGGCGA 2369 TGCAAAAGGCGCGTTTGGGTTCCGCATGC

Fig. 3. Nucleotide sequence of the ampC gene from $P$. immobilis A5 and the deduced amino acid sequence of the $\beta$-lactamase precursor. Amino acids are numbered starting at the $\mathrm{N}$-terminal residue of the native enzyme determined by amino acid sequencing (underlined). The consensus signal peptidase cleavage site is located by a dashed bracket. The four conserved elements of $\beta$-lactamases are boxed; the potential promoter regions $(-35,-10)$ and ribosome-binding site (RBS) are also indicated. 289 352 政 7 ,

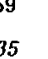

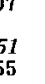

\section{,} 63 $-26$ 然 .3. s. 71 87

要

19
然

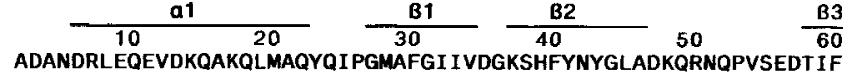
ADANDRLEQEVDKQAKQLMAQVQI PGMAFGI I VDGKSHFYNYGLADKQRNQPVSEDT IF
TPVSEKQLAEVVANT I TPLMKAQSVPGMAVAVIYQGKPHYYTFGKADIAANKPVTPQTLF TPVSEKQLAEVVANT ITPLMKAQSVPGMAVAVI YQGKPHYYTFGKADIAANKPVTPQTLF
TPVSEKQLAEVVANTVT PLMKAQSVPGMAVAVIYQGKPHYYTFGKADIAANKPVTPQTLF PVSEKQLAEVVANTVTPLMKAQSVPGMAVAVIYQGKPHYYTFGKADI AANKPVTPOTLF
APQQI NDI VHRTI TPLIEQQKI PGMAVAVIYQGKPYYFTWGYADIAKKQPVTQQTLF AAKTEQQI ADI VNRT I TPLMQEQAI PGMAVAI I YEGKPYYFTWGKADI ANNHPVTQQTLF GEAPADRLKALVDAAVQPVMKANDI PGLAVAISLKGEPHYFSYGLASKENGRRVTPETLF AQQQDIDAVIQPLMKKYGVPGMAIAVSVDGKQQIYPYGVASKOTGKPITEQTLF

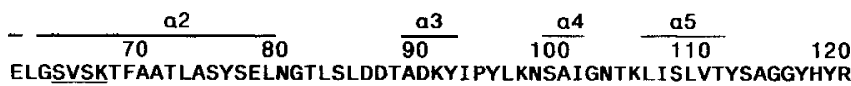
ELGSVSKTFAATLASYSELNGTLSLDDTADKYI PYLKNSAIGNTKL I SLVTYSAGGYHYR
ELGSISKTFTGVLGGDAIARGE I SLDDAVTRYWPQLTGKQWQGIRMLDLATYTAGGLPLQ ELGSISKTFTGVLGGDAIARGE I SLDDAVTRWWPQLTGKQWQGI RMLDLATYTAGGLPLQ
ELGSISKTFTGVLGGDAIARGE I SLDDPVTRYWPQLTGKQWQGI RMLDLATYTAGGLPLQ ELGSVSKTFTGVLGGDAI ARGEIKLSDPTTKYWPELTAKOWNGITLLHLATYTAGGLPLQ ELGSVSKTFNGVLGGDRIARGEI KLSDPVTKYWPELTGKQWRGISLLHLATYTAGGLPLQ EIGSVSKTFTATLAGYALTQDKMRLDDRASQHWPALQGSRFDGISLLDLATYTAGGLPLQ EVGSLSKTFTATLAVYAQQQSKLSFKDPASHYLPDVRGSAFDGVSLLNLATHT-SGLPLF

$\frac{a 6}{130} 140 \quad 150 \frac{a 7}{160} \quad 17 \frac{a 8}{0}$ CLKTL-ENNKELLQYYKSWHPDFPVNSKRLYSNASIGLFGYI SALSMHSOYTKLIENTVL VPDEV - TDNASLLRFYQNWQPOWKPGT TRLYANASIGLFGALAVKPSGMPYEQAMTTRVL VPDEV-TDNASLVRFYQNWQPQWKPGT TRLYANASIGLFGALAVKPSGMPYEQAMTTRVL VPDEV-KSSSDLLRFYQNWQPAWAPGTQRLYANSSIGLFGALAVKPSGLSFEQAMQTRVF I PGDV-TDKAELLRFYQNWQPQWT PGAKRLYANSS I GLFGALAVKSSGMSYEEAMTRRVL FPDSVQKDOAOIRDYYROWOPTYAPGSORLYSNPSIGLFGYLAARSLGOPFERLMEOOVF VPDDV-TNNAQLMAYYRAWQPKHPAGSYRVYSNLGIGMLGMI AAKSLDQPFIQAMEQGML

$-\quad \frac{B 4}{190} \quad 200 \quad 210 \quad \frac{a 9}{220} \quad \frac{B 5}{230} \frac{a 10}{2}$ PSLKMTNTFVDVPANKMEDYAFGYNAAGEPIRVNPGMLDAEAYGI KSTSADMTRFMAANM KPLKLDHTWINVPKAEEAHYAWGY-RDGKAVRVSPGMLDAQAYGVKTNVQDMANWVMANM KPLKLDHTWINVPKAEEAHYAWGY-RDGKAVRVSPGML DAQAYGVKTNVQDMANWVMANM OPLKLNHTWINVPPAEEKNYAWGY-REGKAVHVSPGALDAEAYGVKST IEDMARWVQSNL QPLKLAHTWI TVPQSEQKNYAWGY-IEGKPVHVSPGQLDAEAYGVKSSVI DMARWVQANM PALGLEQTHLDVPEAALAQYAQGYGKDDRPLRVGPGPLDAEGYGVKTSAADLLRFVDANL PALGMSHTYVQVPAAQMANYAQGYSKDDKPVRVNPGPLDAESYGIKSNARDLI RYLDANL

$$
\frac{a 11}{250} \frac{B 6}{260} \quad \frac{B 7}{270} \stackrel{B 8}{280} \frac{a 12}{290}-
$$

GLVTV-DSQMQQALDNNRKGYYRTKSFTQGLAWEMYPLPTTLQQLVEGMSTETI LQPQPI APENVADASLKQG I ALAQSRYWRIGSMYQGLGWEMLNWPVEANTVVEGSDSKVALAPLPV APENVADASLKQG I ALAQSRYWRIGSMYQGLGWEMLNWPVEANT VVEGSDSKVALAPLPV KPLDINEKTLQQG I QLAQSRYWQTGDMYQGLGWEMLDWPVNPDSI INGSDNKIALAARPV DASHVQEK TLQOGI I LAQSRYWR I GDMYQGLGWEMLNWPL KADSI I NGSDSKVALAALPA HPERL-ORPWAOALDATHRGYYYGDMTOGLGWEAYOWPI SLKRIOAGNSTPMALOPHRI QQVKV-ASV-ARRWPRRTSVI TSAGAFTQDLMWENYPYPVKLSRLI EGWNAGMIMNGTPA $\frac{B 9}{310} \frac{B 10}{320} \frac{B 11}{330} \frac{B 12}{340} \frac{014}{350}$ VEVNPPAPPVKASWVHKTGSTGGFGSYVAFI PEKOI GI VMLANT SYPNPARVEAAYH ILE KAITPPTPAVRASWVHKTGATGGFGSYVAFI PEKELGI VMLANKNYPNPARVDAAWOI $L N$ VEVNPPAPAVKASWVHKTGSTGGFGSYVAFVPEKNLGIVMLANKSYPNPARVEAAWRILE ARLPAPOALEGORLLNTGSTOFGAYVAFVPGRDLGLVILANRNYPNAERVKIAYAIL ARLPAPQALEGQRLLNKTGSTNGFGAYVAFVPGRDLGLVI LANRNYPNAERVKIAYAILS
TAI TPPQPELRAGWYNKTGSTGGFSTYAVF I PAKN I AVEMLANKWFPNDDRVEAAYHI IQ
SVMNN
ALQ
ALQ
ALQ
KLQ
GLEQQGKVPLKA
P. immobilis A5
E. cloacae P99
E. cloacae Q908R
E. coli K12
ALEKR
C. freundii 0S60
s. marcescens SR50

Fig. 4. Amino acid sequence alignment of class $\mathrm{C} \boldsymbol{\beta}$-lactamases. Sequences of class $C \beta$-lactamases have been aligned using the Pileup program (GCG). The numbering corresponds to the $C$. freundii enzyme. The secondary structures of E. cloacae P99 $\beta$-lactamase [24] are indicated and the four conserved elements are underlined.

active-site serine is located in a cleft between the two domains at the N-terminus of the $\alpha 2$ helix. The crystal structure of the $E$. cloacae enzyme and the three-dimensional model of $P$. immobilis $\beta$-lactamase were analysed in order to identify the weak interactions and the structural features potentially involved in the low stability and structure flexibility of the psychrophilic enzyme. The results are discussed below.

\section{DISCUSSION}

All pathogenic gram-negative bacteria producing $\beta$-lactamases concentrate the enzyme in the periplasmic space where the penicillin targets are located. By contrast, $P$. immobilis A5 secretes its $\beta$-lactamase to the culture medium. As already mentioned for a closely related strain [7], $\beta$-lactamase secretion is 
probably an ancestral, but weakly efficient, mechanism of protection against bacteriolytic microoganisms. It should be noted that the $P$. immobilis $\beta$-lactamase precursor seems to be composed of a preproenzyme. The small potential propeptide (16 amino acid residues) following the consensus signal peptide (Fig. 3) is possibly involved in the extracellular secretion pathway.

The various structural and kinetic properties of the psychrophilic enzyme relates it to the well-characterized class $C \beta$-lactamases. $P$. immobilis $\beta$-lactamase displays a low apparent optimal temperature of activity and a low thermal stability which are common characteristics of proteins from cold-adapted organisms $[5,6]$. However, the high specific activity usually recorded, which is the main adaptation to catalysis at low environmental temperatures $[25,26]$, is not clearly observed. The temperature dependence of nitrocefin hydrolysis (Fig. 2) marginally favours the psychrophilic $\beta$-lactamase at low temperatures and the kinetic parameters for the hydrolysis of penicillins and cephalosporins (Table 2) are similar to the values determined for mesophilic strains. It should be noted that the comparison is made with highly specialized cephalosporinases from pathogenic bacteria that have evolved under the strong selective pressure of antibiotics: they are themselves a special class of extremophiles. However, the surrounding concentration of $\beta$-lactam antibiotics in the antarctic environment is probably very low and the enzyme could be highly specific to an as-yet unidentified substrate.

The model structure of $P$. immobilis $\beta$-lactamase provides insights into the molecular origin of heat lability. This enzyme possesses the lowest proline content (18 versus $22-27$ residues) and arginine content ( 9 versus $11-24$ residues) when compared with other class $C$ enzymes. Proline contributes to the local rigidity of the peptidic backbone because the pyrrolidine ring severely restricts the available dihedral angles of the preceding residue and decreases the backbone entropy of unfolding. When compared with mesophilic $\beta$-lactamases, substitutions for nonproline residues in the $P$. immobilis enzyme occur mainly in loops connecting secondary structures. Three proline residues are strictly conserved in all mesophilic class $C \beta$-lactamases but are replaced in the psychrophilic enzyme. The substitution Pro18 $\rightarrow \mathrm{Gln}$ (C. freundii numbering) avoids a bend in the $\mathrm{N}$ terminal, solvent-exposed helix $\alpha 1$; substitutions Pro188 $\rightarrow$ His and Pro $122 \rightarrow$ Leu increase the flexibility of the loop between helices $\alpha 5$ and $\alpha 6$ at the entrance of the active site. A structural role for arginine through multiple hydrogen bonds to backbone carbonyl and side-chain oxygens has been proposed [27]. For instance, we noted a typical structural arginine conserved in class C $\beta$-lactamases in position 349 and forming all the five hydrogen bonds allowed by the guanidinium group. Inspection of the crystal structure of $E$. cloacae $\beta$-lactamase reveals 16 arginine-mediated hydrogen bonds whereas only 10 bonds are found in the heat-labile $P$. immobilis enzyme. Nine weakly polar interactions between aromatic rings have been recorded in the mesophilic $\beta$-lactamase structure using the parameters given by Burley and Petsko [28]. These interactions are strongly conserved in all class $\mathrm{C}$ enzymes underlining their critical role in $\beta$-lactamase conformation. However, two interactions involving Trp101 (with Tyr135 and Trp138) and Trp276 (with Tyr354) are specifically lacking in $P$. immobilis $\beta$-lactamase. Chromosomally encoded class $C \beta$-lactamases from mesophilic bacteria in general are basic proteins but the psychrophilic enzyme displays an acidic pl arising from 5-6 extra acidic side chains. Similar discrepancies in pl values have been recorded between a psychrophilic subtilisin and its mesophilic or thermophilic counterparts [25]. In that case, it was expected that improved solvent interactions through additional surface acidic residues can destabilize the external shell of the protein. The clustering of these solvent-exposed amino acids within the first 30 residues of $P$. immobilis $\beta$-lactamase and the lack of a conserved proline in helix $\alpha 1$ would reduce the packing (or contacts) of the N-terminal extremity in the $\alpha / \beta$ domain. The hydrophobic effect is a well-recognized determinant of folding stability [29]. Ikai [30] has correlated an aliphatic index, calculated from the molar ratio and the relative volume of Ala, Val, Ile and Leu, with the stability of thermophilic proteins. This index frequently reaches $90-100$ in thermophiles and ranges between $81-86$ in mesophilic class $C \beta$-lactamases; the aliphatic index decreases to 77 for the the cold-adapted enzyme suggesting a lower global hydrophobicity. In addition, the prefered amino acid exchanges have been determined by exchange matrixes according to [31, 32]. The most-favoured residue exchanges from the psychrophilic to the mesophilic $\beta$-lactamases were Asn $\rightarrow$ Gly, Arg, Gln; Ser, Gln $\rightarrow$ Ala ; Lys $\rightarrow$ Arg; Met, Val $\rightarrow$ Leu. All the substitutions decrease the hydrophobicity of the antarctic enzyme when using the PRIFT scale [33], except the Asn $\rightarrow$ Gln replacement. The same conclusion applies when the statistical analysis is restricted to $\alpha$-helices, with Ser, Gln $\rightarrow$ Ala being the preferred exchanges. These substitutions also decrease the flexibility index and the $\alpha$ helix-forming ability of individual amino acids.

The structure of $E$. cloacae $\beta$-lactamase is stabilized by relatively few salt bridges: two ion pairs bonding distant parts of the molecule (Glu82-Arg177 and Arg105-Glu300) and a cluster of electrostatic interactions (His186-Glu195, Lys193Glu196 and Glu195-His198). Only one salt bridge (Lys195Asp198) is found in the psychrophilic enzyme. One should note however that $P$. aeruginosa and Serratia marcescens $\beta$-lactamases also lack these bonds and therefore no conclusions can be drawn. No significant differences were observed in chargedipole interactions within $\alpha$-helices of the class $\mathrm{C} \beta$-lactamases.

In conclusion, several structural factors and weak interactions likely to promote enzyme stability are specifically lacking in $P$. immobilis $\beta$-lactamase. The disappearance of these stabilizing elements affect all regions of the enzyme molecule, rather than a specific domain, and seems to be involved in the marked heat lability and the expected conformational flexibility of the cold-adapted $\beta$-lactamase. It is worth mentioning that the same factors have been implicated in the stability of thermophilic proteins, i.e. an increase of proline residues in loops $[34,35]$ and of the Arg molar ratio [36], the reinforcement of aromatic-aromatic interactions [37] and of the hydrophobic effect [38], the occurrence of several salt-bridged surface residues $[39,40]$, interactions preventing unzipping of peptidic terminii [41] and a statistical tendency to increase hydrophobicity, rigidity and $\alpha$-helixforming ability of residues in $\alpha$-helices $[31,32]$. Obviously, the required compromise between enzyme activity at extreme temperatures and the molecular dynamic (flexibility/rigidity) is reached through the same adaptational strategies.

We thank Prof. J. M. Frère for constant interest in this work. The Institut Français pour la Recherche et la technologie Polaire is also acknowleged for the support and facilities offered at the antarctic station Dumont d'Urville. This work was supported in part by the Actions Concertées with the Belgian Government (convention no. 93/98-170), the Région Wallonne [convention no. 1828) and the EU (Network no. ERBCHRXCT940521)

\section{REFERENCES}

1. Morita, R. Y. (1975) Psychrophilic bacteria, Bacteriol. Rev. 39, 144-167.

2. Russell, N. J. (1992) Physiology and molecular biology of psychrophilic microorganisms, in Molecular biology and biotechnology of extremophiles (Herbert, R. A. \& Sharp, R. J., eds) pp. 203224, Blackie, London. 
3. Low, P. S., Bada, J. L. \& Somero, G. N. (1973) Temperature adaptation of enzymes: roles of the free energy, the enthalpy, and the entropy of activation, Proc. Natl Acad. Sci. USA 70, 430-432.

4. Hochachka, P. W. \& Somero, G. N. (1984) Biochemical adaptations, Princeton University Press, Princeton NJ.

5. Arpigny, J. L., Feller, G., Davail, S., Genicot, S., Narinx, E., Zekhnini, Z. \& Gerday, C. (1994) Molecular adaptations of enzymes from thermophilic and psychrophilic organisms, Adv. Comp. Environ. Physiol. 20, 269-295.

6. Feller, G., Narinx, E., Arpigny, J. L., Aittaleb, M., Baise, E., Genicot, S. \& Gerday, C. (1996) Enzymes from psychrophilic organisms, FEMS Microbiol, Rev. 18, 189-202.

7. Feller, G., Sonnet, P. \& Gerday, C. (1995) The $\beta$-lactamase secreted by the antarctic psychrophile Psychrobacter immobilis A8, Appl. Environ. Microbiol. 61, 4474-4476.

8. Ghuysen, J. M. (1991) Serine beta-lactamases and penicillin-binding proteins, Annu. Rev. Microbiol. 45, 37-67.

9. Lamotte-Brasseur, J., Knox, J. R., Kelly, J. A., Charlier, P., Fonzé, E., Dideberg, O. \& Frère, J. M. (1994) The structures and catalytic mechanisms of active-site serine $\beta$-lactamases, Biotechnol. Genet. Eng. Rev. 12, 189-230.

10. Frère, J. M. (1995) Beta-lactamases and bacterial resistance to antibiotics, Mol. Microbiol. 16, 385-395.

11. Galleni, M. \& Frère, J. M. (1988) A survey of the kinetic parameters of class C $\beta$-lactamases. Penicillins, Biochem. J. 255, 119-122.

12. Galleni, M., Amicosante, G. \& Frère, J. M. (1988) A survey of the kinetic parameters of class $C \beta$-lactamases. Cephalosporins and other $\beta$-lactam compounds, Biochem. J. 255, 123-129.

13. Cartwright, S. J. \& Walley, S. G. (1984) Purification of $\beta$-lactamases by affinity chromatography on phenylboronic acid-agarose, Biochem. J. 221, 505-512.

14. O'Callaghan, C., Morris, A., Kirby, S. \& Shingier, A. (1972) Novel method for detection of $\beta$-lactamases by using a chromogenic cephalosporin substrate, Antimicrob. Agents Chemother. 1, 283288.

15. Spratt, B. G., Hedge, P. J., te Heesen, S., Edelman, A. \& BroomSmith, J. K. (1986) Kanamycin-resistant vectors that are analogues of plasmids pUC8, pUC9, pEMBL8 and pEMBL9, Gene (Amst.) 41, 337-342.

16. Feller, G., Thiry, M., Arpigny, J. L. \& Gerday, C. (1991) Cloning and expression in Escherichia coli of three lipase-encoding genes from the psychrophilic antarctic strain Moraxella TA144, Gene (Amst.) $102,111-115$.

17. Sutcliffe, M. J., Haneef, I., Carney, D. \& Blundell, T. L. (1987) Knowledge based modelling of homologous proteins, part I: three-dimensional frameworks derived from the simultaneous superposition of multiple structures, Protein Eng. 1, 377-384.

18. Sutcliffe, M. J., Hayes, F. R. F. \& Blundell, T. L. (1987) Knowledge based modelling of homologous proteins, part II: rules for the conformations of substituted sidechains, Protein Eng. 1, 385392.

19. Pearlman, D. A., Case, D. A., Caldwell, J. W., Ross, W. S., Cheatham, T. E., Ferguson, D. M., Seibel, G. L., Singh, U. C., Weiner, P. K. \& Kollman, P. A. (1995) AMBER 4.1, University of California, San Francisco.

20. Feller, G., Narinx, E., Arpigny, J. L., Zekhnini, Z., Swings, J. \& Gerday, C. (1994) Temperature dependence of growth, enzyme secretion and activity of psychrophilic antarctic bacteria, Appl. Microbiol. Biotechnol. 41,477-479.

21. Von Heijne, G. (1985) Signal sequences, the limits of variation, $J$. Mol. Biol. 184, 99-105.

22. Joris, B., Ledent, P., Dideberg, O., Fonzé, E., Lamotte-Brasseur, J., Kelly, J. A., Ghuysen, J. M. \& Frère, J. M. (1991) Comparison of the sequences of class-A beta-lactamases and of the secondary structure elements of penicillin-recognizing proteins, Antimicrob. Agents Chemother. 35, 2294-2301.

23. Oefner, C., D'Arcy, A., Daly, J. J., Gubernator, K., Charnas, R. L., Heinze, I., Hubschwerlen, C. \& Winkler, F. K. (1990) Refined crystal structure of $\beta$-lactamase from Citrobacter freundii indi- cates a mechanism for $\beta$-lactam hydrolysis, Nature 343, 284288.

24. Lobkovsky, E., Moews, P. C., Liu, H., Zhao, H., Frère, J. M., Knox, J. R. (1993) Evolution of an enzyme activity: crystallographic structure at $2 \AA$ resolution of cephalosporinase from the ampC gene of Enterobacter cloacae P99 and comparison with a class A penicillinase, Proc. Natl Acad. Sci. USA 90, 11257-11261.

25. Davail, S., Feller, G., Narinx, E. \& Gerday, C. (1994) Cold adaptation of proteins. Purification, characterization and sequence of the heat-labile subtilisin from the antarctic psychrophile Bacillus TA41, J. Biol. Chem. 269, 17448-17453.

26. Feller, G., Lonhienne, T., Deroanne, C., Libioulle, C., Van Beeumen, J. \& Gerday, C. (1992) Purification, characterization, and nucleotide sequence of the thermolabile $\alpha$-amylase from the antarctic psychrotroph Alteromonas haloplanctis A23, J. Biol. Chem. 267, 5217-5221.

27. Borders, C. L., Broadwater, J. A., Bekeny, P. A., Salmon, J. A., Lee, A. S., Eldridge, A. M. \& Pett, V. B. (1994) A structural role for arginine in proteins: multiple hydrogen bonds to backbone carbonyl oxygens, Protein Sci. 3, 541-548.

28. Burley, S. K. \& Petsko, G. A. (1988) Weakly polar interactions in proteins, Adv. Protein Chem. 39, 125-189.

29. Creighton, T. E. (1991) Stability of folded conformations, Curr. Opin. Struct. Biol. 1, 5-16.

30. Ikai, A. (1980) Thermostability and aliphatic index of globular proteins, J. Biochem. (Tokyo) 88, 1895-1898.

31. Argos, P., Rossman, M. G., Grau, U. M., Zuber, H., Frank, G. \& Tratschin, J. D. (1979) Thermal stability and protein structure, Biochemistry 18, 5698-5703.

32. Menendez-Arias, L. \& Argos, P. (1989) Engineering protein thermal stability; sequence statistics point to residue substitutions in $\alpha$ helices, J. Mol. Biol. 206, 397-406.

33. Cornette, J. L., Cease, K. B., Margalit, H., Spouge, J. L., Berzofsky, J. A. \& DeLisi, C. (1987) Hydrophobicity scales and computational techniques for detecting amphipathic structures in proteins, J. Mol. Biol. 195, 659-685.

34. Watanabe, K., Chishiro, K., Kitamura, K. \& Suzuki, Y. (1991) Proline residues responsible for thermostability occur with high frequency in the loop regions of an extremely thermostable oligo1,6-glucosidase from Bacillus thermogiucosidasius KP1006, J. Biol. Chem. 266, 24287-24294.

35. Watanabe, K., Masuda, T, Ohashi, H., Mihara, H. \& Suzuki, Y. (1994) Multiple proline substitutions cumulatively thermostabilize Bacillus cereus ATCC7064 oligo-1,6-glucosidase, Eur. J. Biochem. 226, 277-283.

36. Merkler, D. J., Farrington, G. K. \& Wedler, F. C. (1981) Protein thermostability, Int. J. Peptide Protein Res. I8, 430-442.

37. Teplyakov, A. V., Kuranova, I. P., Harutyunyan, E. H., Vainshtein, B. K., Frömmel, C., Höhne, W. E. \& Wilson, K. S. (1990) Crystal structure of thermitase at $1.4 \AA$ resolution, J. Mol. Biol. $2 / 4$. $261-279$

38. Mozhaev, V. V., Berezin, I. V. \& Martinek, K. (1988) Structurestability relationship in proteins: fundamental tasks and strategy for the development of stabilized enzyme catalysts for biotechnology, CRC Crit. Rev. Biochem. 23, 235-281.

39. Walker, J. E., Wonacott, A. J. \& Harris, J. I. (1980) Heat stability of a tetrameric enzyme, D-glyceraldehyde-3-phosphate dehydrogenase, Eur. J. Biochem. 108, 581-586.

40. Hennig, M., Darimont, B., Sterner, R., Kirschner, K. \& Jansonius, J N. (1995) $2.0 \AA$ structure of indole-3-glycerol phosphate synthase from the hyperthermophile Sulfolobus solfataricus: possible determinant of protein stability, Structure (Lond.) 3, 1295-1306.

41. Blake, P. R., Park, J. B., Bryant, F. O., Aono, S., Magnuson, J. K., Accleston, E., Howard, J. B., Summers, M. F. \& Adams, M. W. W. (1991) Determinants of protein hyperthermostability: purification and amino acid sequence of rubredoxin from the hyperthermophilic archaebacterium Pyrococcus furiosus and secondary structure of the zinc adduct by NMR, Biochemistry 30,1088510895 . 